\title{
NUEVAS TECNOLOGÍAS EN EL DESARROLLO DE CELDAS SOLARES
}

New Technologies on Solar Cells Development

Mg. Ing. Julio González Prado

\section{RESUMEN}

La energía solar fotovoltaica es la forma de energía renovable más utilizada y que puede ser utilizada en múltiples aplicaciones, tanto domesticas como industriales. El desarrollo de esta tecnología se debe básicamente a la evolución que ha tenido el diseño y fabricación de las celdas solares.

El presente trabajo plantea dar a conocer las características de las celdas solares, sus principales aplicaciones y los nuevos materiales que se utilizan en su fabricación, lo que permite el desarrollo mejores características en ellas.

Palabras clave: energía fotovoltaica, célula fotoeléctrica, radiación solar, captadores solares, placa absorbente, central térmica solar.

\begin{abstract}
Photovoltaic solar energy is the most used form of renewable energy and that can be used in multiple applications both domestic and industrial. The development of this technology it basically due to the evolution that the design and manufacture of solar cells has had.

The present work proposes to present the characteristics of solar cells its main applications as well as the new materials used in his manufacture what allows the development of solar cells with better characteristics.
\end{abstract}

Key words: photovoltaic energy, photoelectric cell, solar radiation, solar collectors, absorbent plate, solar thermal power plant. 


\section{INTRODUCCIÓN}

La energía solar fotovoltaica es la forma de energía alternativa más usada en la actualidad por la abundancia con que se presenta en la naturaleza. También, influye en la aplicación las diversas tecnologías que se están desarrollando para su aprovechamiento. Estas consideran las mejoras en la fabricación de los materiales que constituyen los paneles solares, que han superado largamente la eficiencia de aquellos fabricados inicialmente con fines experimentales.

\section{DESARROLLO}

El uso de la energía solar fotovoltaica se ha generalizado, debido a que es una forma abundante de energía renovable. Por ello, se han desarrollado tecnologías que permitan su aprovechamiento.

Entre estas nuevas técnicas, se pueden encontrar las plantas de concentración fotovoltaicas, en las cuales se sustituye el material semiconductor por nuevos materiales reflectantes o refractantes, con que se logra un grado de concentración de hasta 1000.

Se deben mejorar, también, los sistemas de seguimiento para hacerlos más precisos y que permitan una mejor captación de la energía solar durante una mayor cantidad de horas diarias.

Diseñar un sistema de energía alternativa de uso industrial implica que sea económicamente viable. Los costos (por KWh) de células de silicio cristalino disminuyen con los nuevos métodos de fabricación.

El valor promedio de depreciación es de 20 años y el de vida útil de los sistemas, de 30 años. Ello permite un margen de funcionamiento en ganancia de 10 ańos. Esto ocurre si se consideran los actuales métodos de fabricación, pero, si las tecnologías o materiales mejoran, el beneficio se puede ampliar. Además el costo de fabricación de los paneles solares está disminuyendo.

La generación de energía eléctrica a partir del proceso de conversión fotovoltaica se genera en una central térmica solar, que es una instalación industrial que realiza el calentamiento de fluido a través de la radiación solar y, por medio del uso del ciclo térmico convencional, produce la potencia necesaria para mover un alternador de generación de energía eléctrica.

Todos estos conceptos definen el marco teórico con el cual se desarrollará este proyecto de tesis, que busca diseñar un proceso que permita definir sistemas de generación eléctrica a nivel industrial de manera económica.

Dado que dichos sistemas están definidos por procedimientos de generación ya utilizados, nuestra investigación se centrará en el uso de nuevos materiales o aplicaciones que posibiliten la aplicación de la energía fotovoltaica en instalaciones industriales en el Perú.

El concepto de nuevas tecnologías implica no solo el uso de materiales inéditos, sino también el diseño y aplicación de los sistemas y metodologías ya utilizadas, que puedan aplicarse de una forma más adecuada en las pequeñas industrias de la zona.

El elemento básico del sistema es la célula fotovoltaica, formada por una lámina semiconductora y una deposición de metales sobre un sustrato denominado "capa fina”. Asimismo, se están realizando pruebas a nivel de laboratorio con materiales orgánicos. La lámina se encapsula en material plástico transparente para crear un bloque que sea aislante, antihumedad, transparente y robusto. A esto se añade el dispositivo conversor y las conexiones eléctricas.

La corriente eléctrica generada es continua y, por medio de un inversor electrónico, se convierte en alterna. De esa manera, puede ser usada en forma directa o por medio de la red comercial.

En forma simplificada, el proceso se resume de la siguiente manera: 
Se genera energía de baja tensión $(380$ - 800 V) y corriente continua. La forma de volverla aprovechable es convirtiéndola en corriente alterna por medio de un inversor. Dicha energía, en el centro de transformación, se eleva a media tensión $(15-25 \mathrm{Kv})$ para ser insertada en la red eléctrica, de modo que pueda ser aprovechada.

\section{PANELES FOTOVOLTAICOS}

Llamados también paneles solares, son conjuntos de células fotovoltaicas que producen electricidad por la luz solar que reciben mediante el efecto fotoeléctrico.

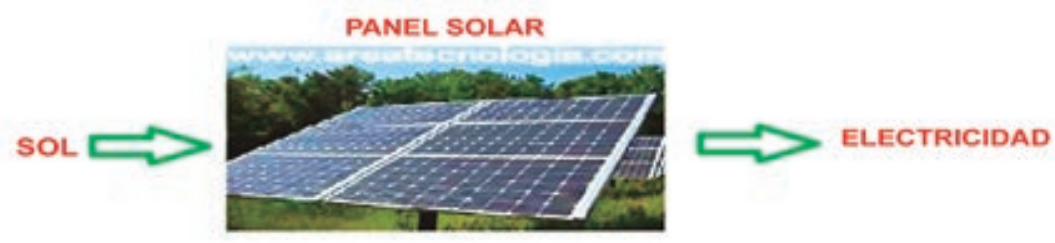

Figura 1. Funcionamiento de un panel solar. Adaptado de “¿Qué son los paneles solares?”, por Área Tecnología, 2018, en http://www.areatecnologia.com/electricidad/paneles-solares.html

Los paneles solares se clasifican de acuerdo con el tipo de célula que los conforma:

En primer lugar, las células cristalinas pueden ser las siguientes:

- Las monocristalinas, que se componen de secciones de un cristal único de silicio;

- Policristalinas, que están constituidos por conjuntos de estructuras de varios tipos de cristales.

En segundo lugar, las células amorfas se componen de silicio no cristalizado.

La efectividad de la conversión depende de diferentes parámetros: el área de recepción de la radiación solar (cuanto mayor sea el contacto, mejor será la efectividad), la geometría y el costo de los materiales.

El rendimiento promedio de las células cristalinas puede llegar a 22\%, mientras que el de las células amorfas, al 10\%. La diferencia radica en que los costos y el peso de las células amorfas son muy inferiores.

\section{EFECTO FOTOELÉCTRICO}

El efecto fotoeléctrico es el fenómeno por el cual el haz de partículas de luz, compuesto por fotones, incide en los electrones de un metal y les proporciona energía que los arranca de la configuración. Este proceso de movilidad de electrones genera la corriente eléctrica.

\section{GENERACIÓN DEL EFECTO FOTOELÉCTRICO}

En la naturaleza existen tres tipos de elementos: aislantes, semiconductores y conductores. Las características de cada uno de ellos dependen de la banda de conducción (BC) y la banda de valencia (BV). Entre ambas bandas, se ubica la zona vacía (o GAP). Además, no se debe olvidar la importancia de los electrones de valencia para determinar sus características. 


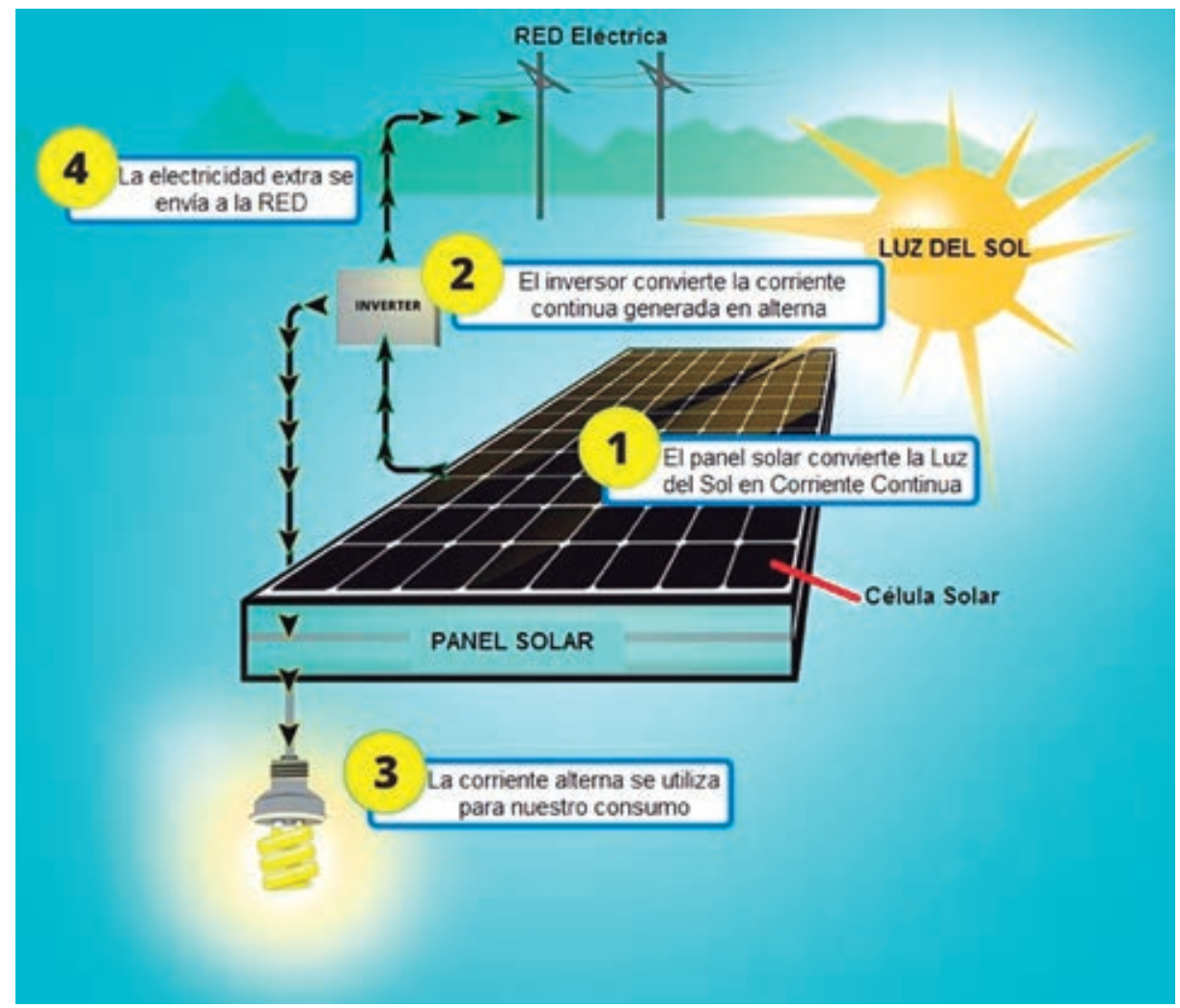

Figura 2. Conexión de la red eléctrica con el panel solar. Adaptado de "¿Qué son los paneles solares?", por Área Tecnología, 2018, en http://www.areatecnologia.com/electricidad/paneles-solares. html

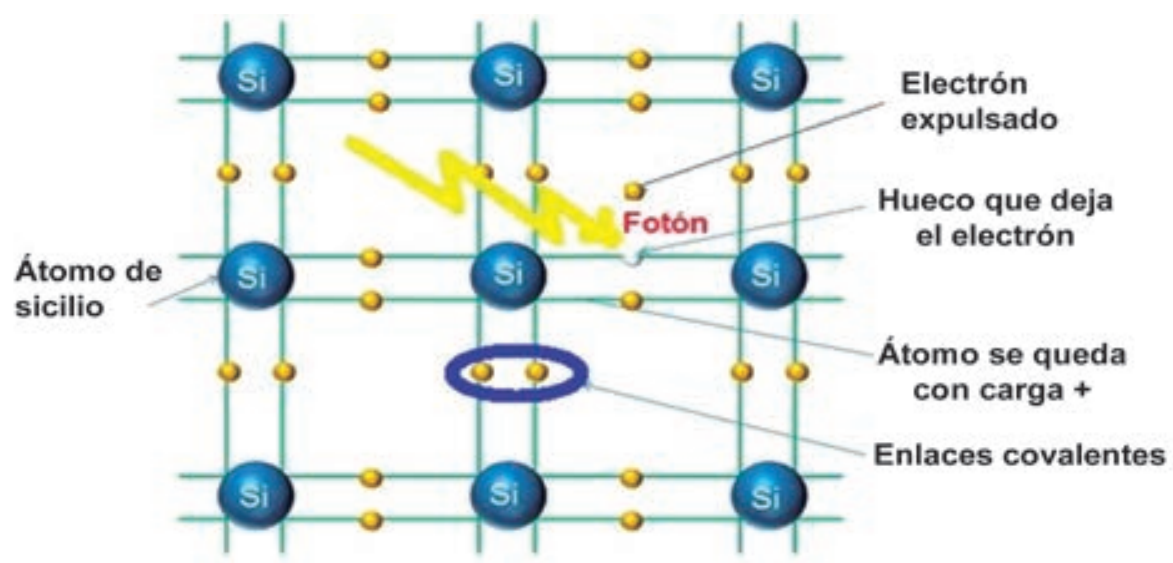

Figura 3. Estructura atómica de un elemento semiconductor (Si). Adaptado de “Qué son los paneles solares?”, por Área Tecnología, 2018, en http://www.areatecnologia.com/electricidad/paneles-solares.html 
En la banda de conducción, se encuentran los electrones de valencia que pueden moverse libremente por tener gran cantidad de energía.

En los elementos aislantes, la banda de conducción está vacía, porque todos los electrones, incluidos los de la última capa, están ligados al átomo, tienen energía más baja y están ubicados en la banda de valencia.

Los que se encuentran en la banda de valencia no pueden pasar a la de conducción por dos razones: tienen baja energía y la zona vacía o GAP es considerablemente grande.

En los elementos conductores, la banda de conducción y la de valencia se traslapan. No existe GAP y, por lo tanto, los electrones de valencia pueden escapar de la configuración con facilidad.

En los elementos semiconductores, la zona vacía es poco significativa y los electrones de valencia pueden escapar de la configuración de acuerdo con ciertas condiciones. En un semiconductor de tipo $\mathrm{N}$, los electrones de la banda de conducción son los que tienen más energía. En uno de tipo P, hay muy pocos electrones en la banda de conducción, así que deben considerarse los electrones de la banda de valencia.

A la temperatura ambiente, los electrones con mayor energía se encuentran cerca del nivel de Fermi. La energía que se debe proporcionar a un electrón para que salga al exterior desde ese nivel se llama "función de trabajo» y la frecuencia mínima necesaria de radiación incidente para sacar un electrón del metal se llama «frecuencia umbral».

El efecto fotoeléctrico fue uno de los primeros efectos físicos que demostró la dualidad onda/ corpúsculo, característica de la mecánica cuántica. La luz se comporta como onda, así que puede producir interferencias y difracción, pero intercambia energía de forma discreta en paquetes de energía denominados fotones, cuya energía depende de la frecuencia de la radiación electromagnética.

El silicio es el material semiconductor más usado en la fabricación de las celdas fotovoltaicas.

Este elemento, en su estado puro, tiene cuatro electrones de valencia, que comparte con los átomos vecinos para formar enlaces covalentes. Si se añaden impurezas con más o menos electrones de valencia (fósforo, 5; boro, 3) se modifican las propiedades conductoras del silicio.

\section{SICILIO DOPADO}

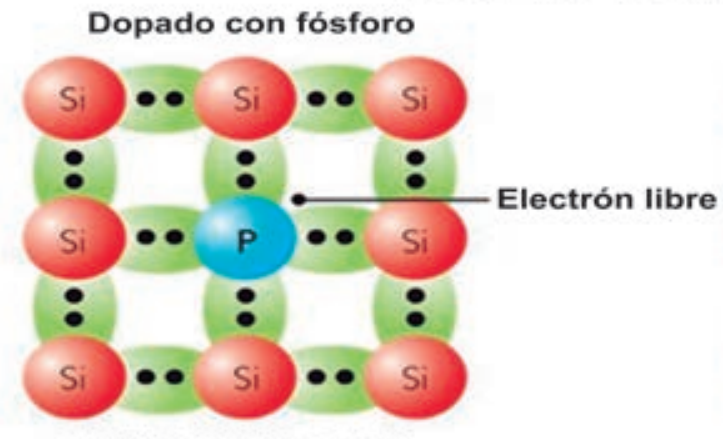

SEMICONDUCTOR N

Portadores de carga electrones

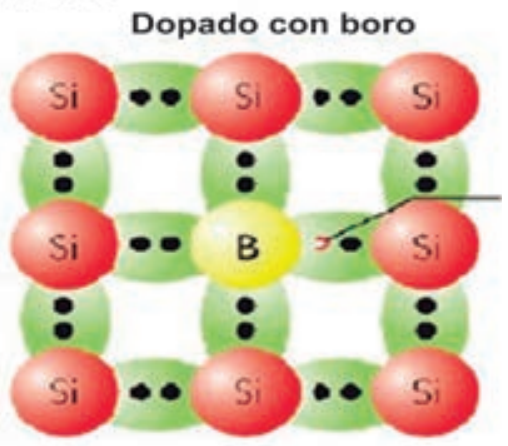

SEMICONDUCTOR P Portadores de carga huecos

Figura 4. Estructura del Silicio dopado. Adaptado de “Qué son los paneles solares?”, por Área Tecnología, 2018, en http://www.areatecnologia.com/electricidad/paneles-solares.html 


\section{SEMICONDUCTOR EXTRÍNSECO TIPO N}

Este se produce al dopar (introducir), en la estructura cristalina del Si, un elemento de cinco electrones de valencia en su orbital externo: fósforo (P), antimonio (Sb) o arsénico (As). Como se aprecia en la imagen, el átomo de P crea los cuatro enlaces covalentes y le sobra un electrón, que sale de su órbita para que quede estable. Por lo tanto, por cada átomo de P, aparece un electrón libre, y la estructura aumenta su conductividad eléctrica. Se denominan conductores tipo N, debido a que la carga de los portadores es negativa.

\section{LA JUNTURA PN}

La unión de estos dos tipos de semiconductores define lo que se denomina la juntura PN, que es un material con características propias que definen su funcionamiento debido a las condiciones que se presentan.
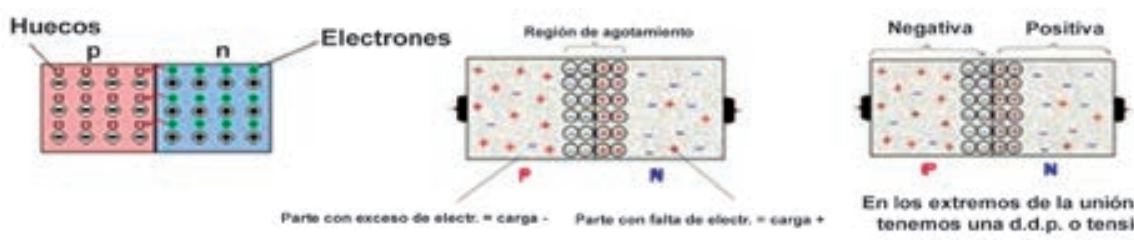

En los extremos de la unión P-N tenemos una d.d.p. o tension

Figura 5. Características de la juntura p-n. Adaptado de “Qué son los paneles solares?”, por Área Tecnología, 2018, en http://www.areatecnologia.com/electricidad/paneles-solares. html

Este material ha sido la base de todos los dispositivos semiconductores que se han desarrollado a lo largo de los ańos.

En el caso de los paneles solares, una aproximacion bastante simple es la que se muestra en la siguiente figura:

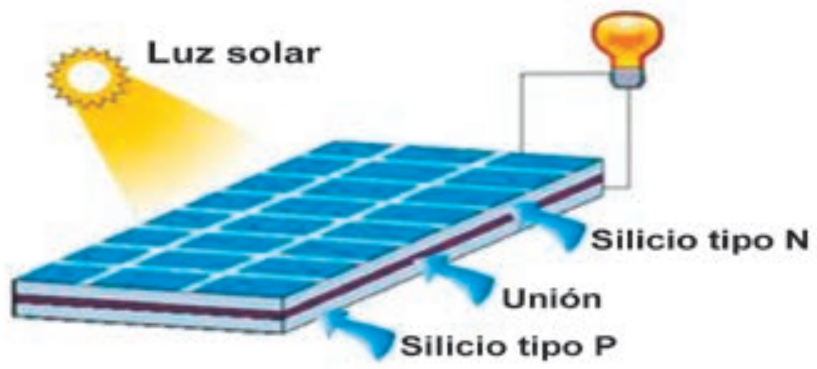

Figura 6. Esquema de paneles solares. Adaptado de “Qué son los paneles solares?”, por Área Tecnología, 2018, en http://www.areatecnologia.com/electricidad/paneles-solares.html 
En cuanto al esquema de funcionamiento, obsérvese la siguiente figura:
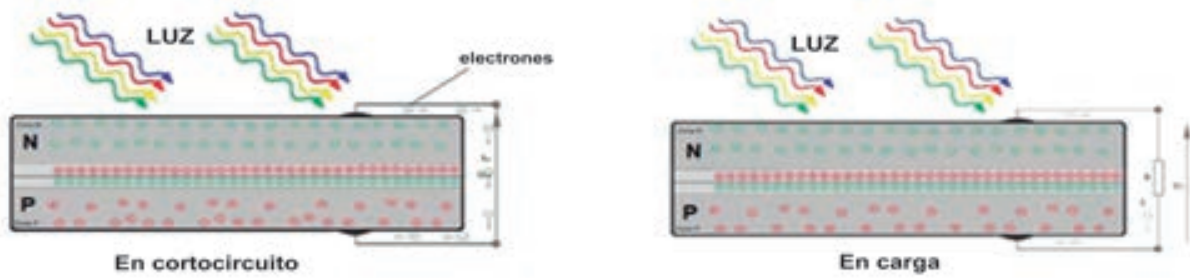

Figura 7. Esquema de funcionamiento de juntura PN. Adaptado de “Qué son los paneles solares?”, por Area Tecnología, 2018, en http://www.areatecnologia.com/electricidad/paneles-solares. html

\section{CELDA SOLAR}

Es el dispositivo que convierte la luz en electricidad, gracias a las propiedades de los semiconductores y a la juntura PN, que permiten extraer los electrones excitados de la célula a un circuito exterior antes de que vuelvan a su estado de equilibrio térmico, de manera que estén aptos para realizar un trabajo.

La celda solar utiliza un haz de fotones a $6000^{\circ} \mathrm{K}$. Es decir, opera como una máquina térmica cuya caldera estuviera a $6000^{\circ} \mathrm{K}$. En una central térmica, el agua se calienta a $900{ }^{\circ} \mathrm{C}$ para crear vapor y las centrales termosolares calientan el agua a $800^{\circ} \mathrm{K}$. Por otro lado, la eficiencia que se puede conseguir con el gas de fotones es del 95\%. Para las centrales térmicas, la eficacia ideal máxima es del 66\%. Lamentablemente, no se pueden fabricar calderas ni piezas para ella, ya que todo el material se funde antes de llegar a esta temperatura.

Las celdas más utilizadas son las de silicio cristalino y multicristalino, ya que utilizan la unión PN y contactos en ambas caras. Además, proporcionan alrededor de 0,5 voltios y una corriente de $35 \mathrm{~mA} /$ $\mathrm{cm}^{2}$ cuando son iluminadas por el sol en un día claro a $1000 \mathrm{~W} / \mathrm{m}^{2}$, que se considera como irradiancia de referencia estándar. Ambos materiales utilizan silicio ultrapuro que se deriva del empleado en la industria microelectrónica.

El silicio multicristalino se forma por solidificación de crisoles de gran tamaño (hasta $500 \mathrm{Kg}$ ) y se diferencia del silicio monocristalino en el que el material resultante es milimétrico. El costo por oblea y la eficiencia son menores, por lo que el precio por vatio pico es similar. Sin embargo, se tiende a la producción de material multicristalino que permita una reducción real del costo.

Otra tecnología de fabricación de celdas es la denominada de "celdas de capa delgada» (thin film solar cells), que agrupa un conjunto de tecnologías de fabricación, entre las cuales, por sus resultados y el desarrollo industrial, se deben considerar las implementadas con teluro de cadmio (CdTe), silicio amorfo (a-Si) y $\mathrm{Cu}(\mathrm{InGa}) \mathrm{Se}_{2}$ (CIGS). Estas son más eficientes, al menos, en pruebas de laboratorio. La principal característica de la energía solar fotovoltaica de capa delgada es la posibilidad de lograr un bajo costo, más que su excelente eficiencia. Su récord, en ese aspecto, siempre fue la mitad que el logrado con el silicio monocristalino.

Otro de los tipos es el que se denomina Si-sheet solar cells (celdas de silicio pelicular), fabricado por la compañía Astropower. Consiste en silicio policristalino elaborado con tecnología de capa delgada.

También se pueden encontrar celdas más eficientes, denominadas "celdas multiunion", de distintos materiales, construidas monolíticamente, es decir, en un solo monocristal continuo. Con ellas, se 
han alcanzado eficiencias de $40.7 \%$ bajo luz concentrada. No obstante, son más caras y se han usado principalmente en aplicaciones para naves espaciales. Actualmente, combinadas con sistemas de concentración, sirven para generación en plantas conectadas a red.

Hay una relación entre la eficiencia del dispositivo y la reducción del costo de la celda solar: al aumentar la primera, disminuye proporcionalmente la superficie del colector (vidrio, encapsulante), los soportes, el terreno, los cables, el transporte, la instalación, etc. Se considera que la eficiencia mínima para que una tecnología pueda ser rentable es del $10 \%$.

\section{CELDAS DE SILICIO CRISTALINO}

Utilizan la sílice, material abundante en la corteza terrestre, que ha sido estudiado en la microelectrónica. Su valor de banda prohibida $(1.1 \mathrm{eV})$ es muy adecuado para la conversión de la luz solar en electricidad. Como es un semiconductor de banda indirecta, se necesita un espesor mayor o igual a 100 micras para absorber la luz, pero su fragilidad determina que las celdas solares se construyan sobre obleas de 300 micras.

Para que los electrones elevados a la banda de conducción no vuelvan a la banda de valencia, antes de que podamos sacarlos para realizar un trabajo, se necesita que el material útil sea de gran pureza y de gran perfeccion estructural para lo cual se emplea material de fabricación microelectrónica y obleas monocristalinas.

En el proceso de cortado de los monocristales o multicristales se pierde mucho material. Una forma de abaratar esto consiste en obtener y procesar obleas de 150 micras. Para evitar el proceso de corte de las obleas a partir de las barras monocristalinas ó multicristalinas, se han desarrollado procedimientos que permiten obtener, directamente desde el baño de silicio fundido cintas planas continuas, aunque su extracción y enfriamiento para obtener la calidad estructural necesaria es lenta y critica.

El costo de abaratar la obtención del polisilicio representa solo el $23 \%$ del costo total de modo que si el polisilicio más barato rebajara la eficiencia final aumentarían los costes restantes que representan el $77 \%$ restante.

Si extendemos esta consideración al sistema fotovoltaico completo, ya instalado, vemos que el peso total del material es solo del $10 \%$ de modo que el impacto del precio del polisilicio es todavía bajo.

En el laboratorio se han obtenido celdas de Si del 25\% con estructuras casi ideales. Sin embargo, con los procesos de fabricación establecidos por la industria, se logra hasta el 15\% para Si monocristalino y $13 \%$ para el multicristalino. En módulos, el porcentaje se reduce a 14 y $12 \%$ para cada caso.

La clave de la producción rentable es el rendimiento de producción, el porcentaje de obleas que acaban convirtiéndose en celdas solares. Esa cifra es del 95\%. Muchas tecnologías, supuestamente baratas, fracasan en este aspecto, pues obtienen un alto nivel de rechazo o rotura.

\section{NUEVOS MATERIALES: PEROVSKITA}

Perovskita es el nombre de los materiales que presentan una estructura cristalina en forma de cubo con las esquinas recortadas.

Estos se encuentran en diferentes configuraciones y tienen múltiples aplicaciones en la industria, aunque no todas sean adecuadas para la fabricación de las celdas solares. En la actualidad, se utilizan las que se componen de plomo, alkil-amonio, yoduro y clorito.

El uso de perovskita en paneles solares es reciente y suele sustituir al silicio. Los resultados arrojan que la eficiencia ha aumentado del $5 \%$ al $15 \%$ en cinco ańos de experiencia académica. En la 
Universidad de Oxford, por ejemplo, se ha conseguido una celda solar que utiliza óxido de titanio y grafeno para transportar electrones, y perovskitas para absorber la luz. Los procesos se realizan con 150 grados de temperatura y la eficiencia llega al $15 \%$.

El reemplazo del silicio por perovskita tiene las siguientes ventajas:

- No requiere procesos químicos tan complejos y costosos como el silicio, ya que este necesita ser cristalizado y procesado con intervenciones químicas complejas y de altas temperaturas (que son costosas).

- Se requiere menor cantidad de material para implementar una cantidad similar de celdas solares. Una capa de medio micrómetro de espesor de perovskitas equivale a capas de 80 micrómetros de silicio.

- La forma de aplicación también es más sencilla: no se montan en paneles complejos como el silicio, sino que se disuelven por calor. De esa manera, se forma una tinta que se aplica como en una rotativa. El proceso, en forma industrial, se utiliza en la fabricación de pantallas OLED y para lámparas de diodos orgánicos de emisión de luz.

- Otra ventaja es que son flexibles y transparentes, y pueden aplicarse sobre cualquier plástico o cristal.

No obstante, también presenta algunas desventajas:

- Las perovskitas se descomponen cuando están en contacto con la atmosfera, lo que implica que, para ser utilizadas, deben ser selladas.

- Al ser un material nuevo, no se ha podido evaluar su estabilidad a largo plazo.

- No existe una idea uniforme del costo real de fabricación, ya que el proceso de industrialización no está normalizado.

Finalmente, una característica que se considera importante es que los procesos de fabricación y las características de las perovskitas son compatibles con el silicio. Ello permite fabricar paneles con ambos materiales. Al estar elaborados de esa forma, su eficiencia es mayor en tres o cuatro puntos.

\section{ESTRUCTURA MOLECULAR}

Como se dijo anteriormente, el término perovskita se refiere a una estructura, más que a un material en sí. Esta se puede representar por la formula química $\mathrm{ABX} 3$, en la que A y B son cationes (iones con carga positiva) y X es un anión (ion con carga negativa). Un gran catión B en el centro de una estructura cúbica rodeada por seis aniones $\mathrm{X}$ en las caras de un cubo forma un octaedro que, en cada una de sus ocho esquinas, presenta un catión A.

Dependiendo de los átomos o moléculas que se usen en su estructura, la perovskita tiene propiedades diferentes e interesantes.

El material predominante para la fabricación de las celdas solares es $\mathrm{CH}_{3} \mathrm{NH}_{3} \mathrm{PbI}_{3}$ como semiconductor. $\mathrm{CH}_{3} \mathrm{NH}_{3}$ es metilamonio; Pb es un catión de Plomo; $\mathrm{I}_{3}$ es un trioide. Al inicio de las investigaciones, se trató de usar estaño $(\mathrm{Sn})$ en vez de plomo, pero este último resultó mucho más eficiente. Otros posibles haluros para los aniones son el cloro $(\mathrm{Cl})$, el bromo $(\mathrm{Br})$ y hasta el yodo (I), los cuales ofrecen interesantes opciones.

Como la perovskita no es un mineral, su estructura requiere un metal como catalizador y este es el plomo, que se extrae de minerales rocosos que contienen también cobre, zinc o plata: galena $(\mathrm{PbS})$, anglesita $\left(\mathrm{PbSO}_{4}\right)$ y cerrusita $\left(\mathrm{PbCO}_{3}\right)$. 


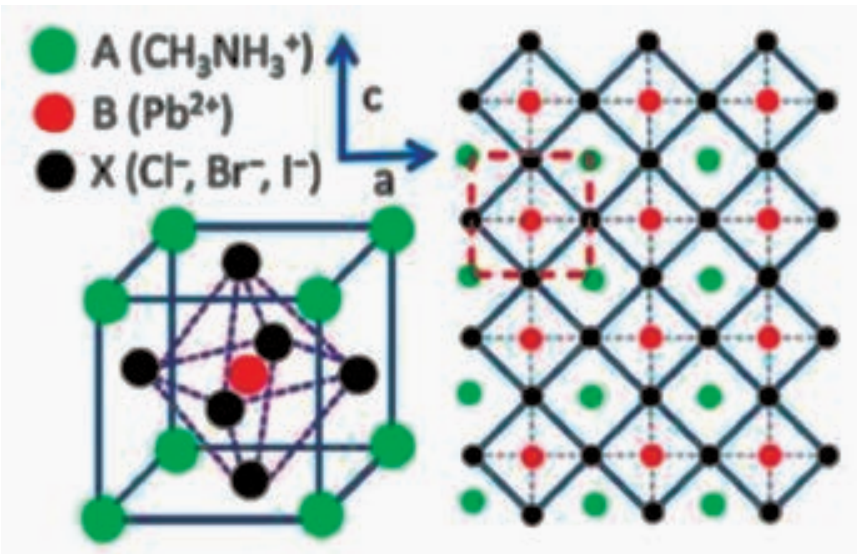

Figura 8. Estructura cristalina de perovskite. Adaptado de "Formation of Thin Films of OrganicInorganic Perovskites for High-Efficiency Solar Cells", por Samuel D. Stranks et al., 2015.

Otro material común en la arquitectura de la celda solar de perovskita es, como en las celdas de $\mathrm{Si}$, el dióxido de titanio $\left(\mathrm{TiO}_{2}\right)$ para el revestimiento anti-reflexión, un marco de aluminio y una cubierta de vidrio. En los contactos eléctricos se utilizan metales como plata-paladio (Ag-Pd), níquel $(\mathrm{Ni})$, o cobre $(\mathrm{Cu})$.

Hay dos tipos principales estructuras de perovskita: la forma planar simple y la meso estructura.

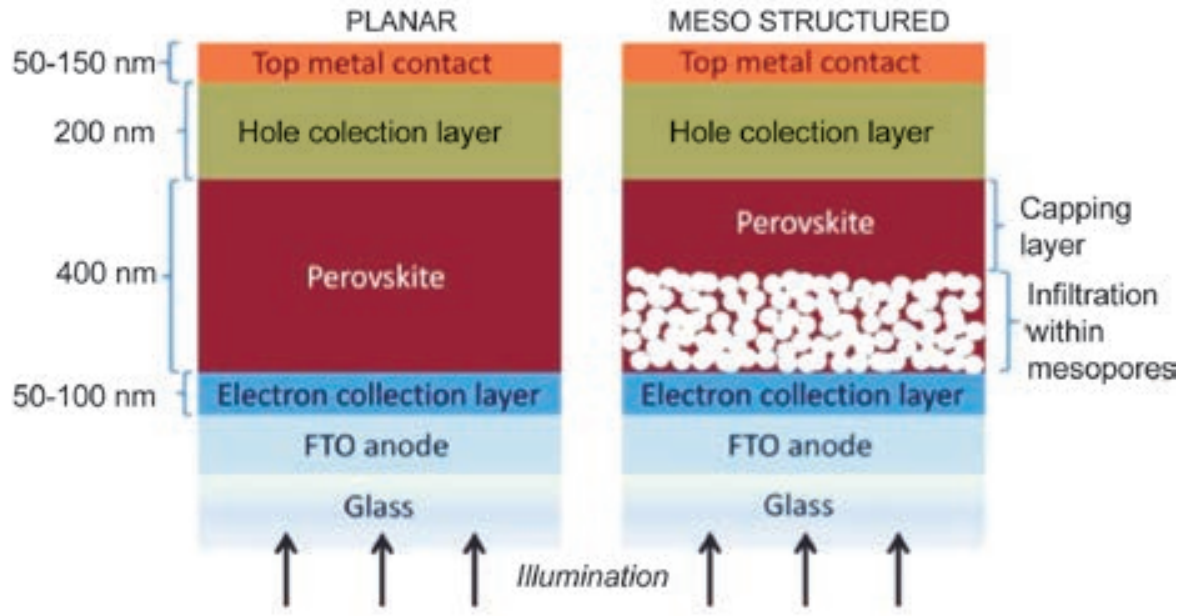

Figura 9. Representación esquemática de dispositivos de arquitectura planar y mesoestructura. Adaptado de "Formation of Thin Films of Organic-Inorganic Perovskites for High-Efficiency Solar Cells", por Samuel D. Stranks et al., 2015. 
a) Estructura planar simple de heterounión: en que la capa de perovskita se ubica entre dos contactos tipo $\mathrm{N}$ y tipo $\mathrm{P}$;

b) Mesoestructura: en que la capa de perovskita se infiltra en los mesoporos del óxido de metal (generalmente, dióxido de Ti).

Ambas estructuras están siendo desarrolladas actualmente, pero es probable que, en un futuro, converjan en una sola.

Algunas de las características que hacen a la celda solar de perovskita atractiva en la fabricación son su bajo costo de producción, y las propiedades ópticas y electrónicas que presenta. Además, la perovskita tiene una alta flexibilidad y una buena absorción de luz sobre todo el rango de emisión solar visible.

Las celdas de perovskita tienen una difusión efectiva sobre los $100 \mathrm{~nm}$, tanto para electrones como para huecos, lo que es relativamente grande y significa que pueden trabajar apropiadamente en una estructura de película delgada.

Además, los displays de perovskita presentan una alta carga de movilidad de portadores y largo tiempo de vida, lo cual es importante para la generación de electrones de luz y huecos con suficiente movilidad para producir corriente sin la pérdida de energía que ocurre al originar calor.

\section{FABRICACIÓN DE CELDAS SOLARES DE PEROVSKITA}

La ventaja de los métodos de fabricación de celdas solares de perovskita sobre las de silicio es su forma más simple y económica, además de que se necesita menos consumo de energía.

Hay dos métodos que se utilizan para fabricar películas de perovskita:

- Procesamiento de solución, que se divide en dos técnicas diferentes;

- $\quad$ Proceso de evaporación al vacío.

Estas técnicas de deposición de perovskvita utilizan una combinación de iodido metilamonio $\left(\mathrm{CH}_{3} \mathrm{NH}_{3} \mathrm{I}\right)$, plomo inorgánico e iodiodo de plomo $\left(\mathrm{PbI}_{2}\right)$.

En ambos procedimientos que utilizan un solvente, la perovskita se deposita en un substrato de recubrimiento por centrifugación.

Uno de los métodos realiza esa operación en un paso y el otro, en dos. El primero disuelve $\mathrm{CH}_{3} \mathrm{NH}_{3} \mathrm{I}$ y $\mathrm{PbI}_{2}$ en un solvente apropiado, y la solución es untada sobre el substrato. En el segundo, el $\mathrm{PbI}_{2}$ se disuelve primero y se unta sobre el sustrato. Luego, la solución de $\mathrm{CH}_{3} \mathrm{NH}_{3} \mathrm{I}$ se ubica encima. En la figura anterior, los solventes representados son dimetilacetamida (DMA), dimetilformamida (DMF) y alcohol isopropílico (IPA).

Se ha encontrado que las perovskitas fabricadas con métodos de dos pasos tienen mejor morfología, lo que permite que las películas generadas tengan una mejor performance fotovoltaica.

Con relación al método de evaporación al vacío, los componentes $\mathrm{CH}_{3} \mathrm{NH}_{3} \mathrm{I}$ y $\mathrm{PbI}_{2}$ se evaporan, en conjunto, alrededor de $150{ }^{\circ} \mathrm{C}$ para preparar la película de perovskita. Este método es más caro, pero presenta algunas ventajas. El control de espesor y la uniformidad de la película generada son mucho mejores. Además, utiliza menos solventes, lo que reduce el riesgo de remanentes de estos últimos.

Otra posibilidad de las películas de perovskita es utilizarlas en conjunto con celdas solares basadas en silicio. Al usarlas de esta forma, se generan películas de dos niveles, en las cuales la perovskita se ubica en la parte superior y las de silicio, en la parte inferior. 

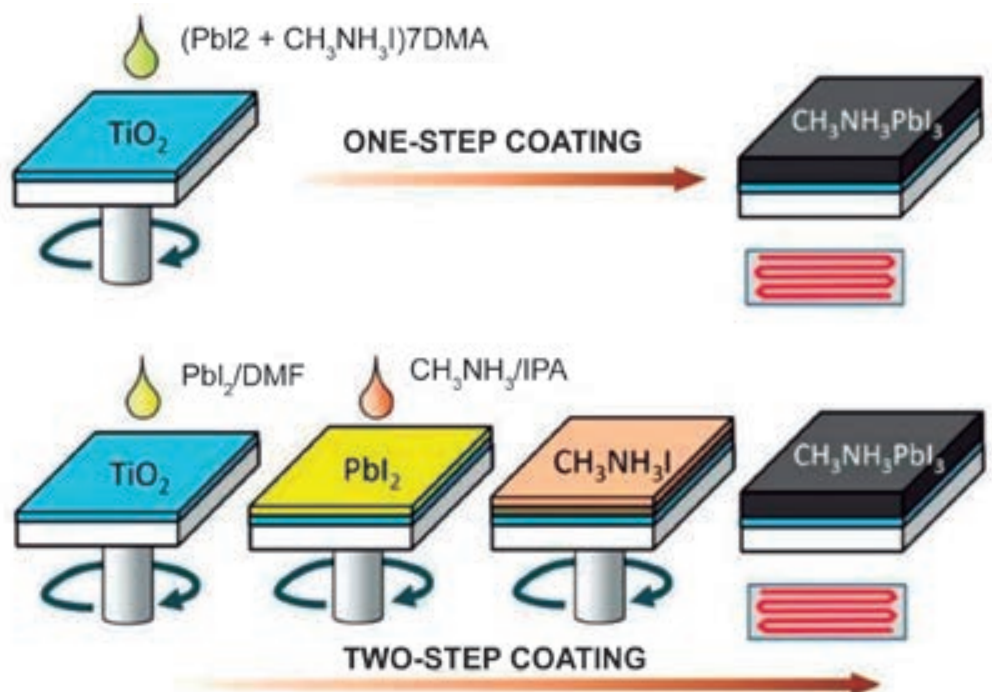

Figura 10. Procedimientos de implementación de deposición de capaz de perovskita. Adaptado de "Perovskite Solar Cells. De Materials to Devices", por Hyun Suk Jung y Nam-Gyu Park, 2014.

\section{DESARROLLOS FUTUROS}

La era de los combustibles fósiles está por terminar, debido a que son elementos que se agotarán en el futuro. En ese sentido, los desarrollos emprendidos se orientan hacia el desarrollo de la energía solar. Por ello, se presenta la disyuntiva entre continuar con las celdas de tecnología de silicio u otorgar mayor énfasis a las celdas con perovskita.

La primera destaca por ser fácil de obtener, prácticamente inacabable y de procesamiento inicial no muy caro. Lo más costoso es el procesamiento final del silicio que será empleado para la fabricación de la celda solar. Además, la última fase de la producción de silicio está limitada por el número de instalaciones de purificación donde se puede realizar el proceso.

Las futuras investigaciones en celdas fotovoltaicas deben considerar si se continúa o se incrementa la inversión en nuevos métodos de purificación de silicio, ya sea monocristalino o policristalino; o se interesa más por el desarrollo de celdas solares de perovskita. El porcentaje de inversión en investigación de las diferentes tecnologías debe ser analizado para diferentes escenarios.

Otra limitación importante que aparece cuando se emplea el silicio es el término de eficiencia de conversión de potencia de las celdas solares. En recientes investigaciones, se ha desarrollado un incremento de ese factor usando perovskita.

Si bien puede parecer más importante incrementar la eficiencia que reducir los costos de los materiales utilizados en la fabricación, hay otros costos que aún se mantienen altos como las instalaciones y el mantenimiento. Los bajos costos son importantes, pero también lo es una alta eficiencia; la perovskita combina ambas características.

Otra particularidad que se debe tomar en cuenta es la capacidad de reciclar los componentes utilizados. Esta es una condición que ha adquirido mucha relevancia en los procesos de fabricación y producción en general. Por lo tanto, se vuelve necesario que, en los procesos de fabricación y mante- 
nimiento, la posibilidad de reciclar los componentes sea discutida y los esfuerzos de investigación se encaminen hacia ese objetivo.

\section{CONCLUSIONES}

- El uso de combustibles fósiles en la generación de energía eléctrica no es una opción favorable en el desarrollo futuro de la industria por las limitaciones y contaminación que genera.

- Las nuevas tecnologías de generación son las llamadas a sustituir a los combustibles fósiles por presentar costos más económicos e implementar sistemas más limpios.

- La tecnología que actualmente se utiliza en la realización de las celdas solares es la basada en silicio, que es la que se ha desarrollado comercialmente.

- Están siendo descubiertos y utilizados nuevos materiales que, en el futuro, podrán reemplazar al silicio como elemento base de las celdas solares.

- Los materiales, tales como la perovskita, tienen mejores características, tanto en el proceso de fabricación como en la cantidad de energía que son capaces de desarrollar.

- Las zonas rurales del llamado "sur chico" tienen muchas condiciones que permiten la implementación, en ellas, de sistemas de generación de energía eléctrica producidas por celdas solares.

\section{BIBLIOGRAFÍA}

[1] J.I. Alonso et al., Energía solar fotovoltaica. Madrid, España: Ed. Colegio Oficial de Ingenieros de Telecomunicación, 2002.

[2] J. Schallemberg et al., Energías renovables y eficiencia energética. Canarias, España: Ed. Instituto Tecnológico de Canarias, 2008.

[3] M. Martínez y K. Cedano, Acercamiento al sol: calor y electricidad para vivir mejor. México: Red Conacyt de Energía Solar, 2017.

[4] "Energías alternativas, guía básica”, 2011. [En línea]. Disponible en: https://formandovalores. files.wordpress.com/2011/11/libro-energc3adas-alternativas.pdf. [Accedido: 10/12/2018]

[5] Instituto para la Diversificación y Ahorro de la Energía, Manual técnico de energía solar para procesos industriales. Madrid, España: Fundación de la Energía de la Comunidad de Madrid, 2012.

[6] «Paneles solares. Instalación de Paneles solares», ONG Fondo Verde, junio 2013. [En línea]. Disponible en: https://www.fondoverde.org/soluciones/proyectos-en-activo/peru/2010/470instalacion-de-paneles-solares\#datos-del-proyecto. [Accedido 10/12/2018]

[7] «Efecto fotoeléctrico y fotovoltaico», MIT Sloan Executive Education, 2015. 